\title{
The use of mitomycin $C$ in caustic esophagitis in rats $^{1}$
}

\author{
Thais França Bustamante, Pedro Luiz Toledo de Arruda Lourenção ${ }^{I I}$, Kátia Leitão Higa ${ }^{\text {III }}$, Amanda Pinter Carvalheiro da \\ Silva ${ }^{\text {III }}$, Erika Veruska Paiva Ortolan ${ }^{\text {IV }}$ \\ IMaster in Surgery, Botucatu Medical School, UNESP, Sao Paulo, Brazil. Conception, design, acquisition and interpretation of data. \\ IIPhD, Assistant Professor, Pediatric Surgery, Surgery and Orthopedic Department, Botucatu Medical School, UNESP, Sao Paulo, Brazil. Interpretation \\ of data, manuscript writing.

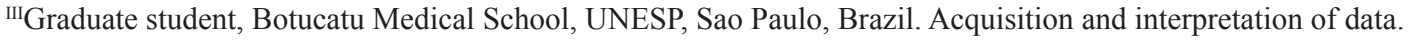 \\ ${ }^{\mathrm{IV}} \mathrm{PhD}$, Assistant Professor, Pediatric Surgery, Surgery and Orthopedic Department, Botucatu Medical School, UNESP, Sao Paulo, Brazil. Supervised \\ all phases of the study, manuscript writing, critical revision.
}

\section{ABSTRACT}

PURPOSE: To evaluate the topical effects of mitomycin C (MMC) in rats, with or without esophageal dilation, in different moments after esophageal caustic injury with $\mathrm{NaOH} 10 \%$.

METHODS: Forty eight Wistar rats were divided into six groups: "GS" infusion of $0.9 \%$ saline solution in the esophagus; "CG" infusion of $0.9 \%$ saline solution in the esophagus, with temporary ligation of the organ; "NTG" induction of a caustic lesion without treatment; "GmmcD0" MMC applied immediately after the caustic injury; "GmmcD14" MMC applied 14 days after the caustic injury; "Gdil+mmcD14" esophageal dilation and application of MMC 14 days after caustic injury. We performed contrast esophagograms of four animals from each group, seven and 21 days after the caustic injury. On day 28, all animals were sacrificed, and histopathological analyses were performed on the esophageal specimens.

RESULTS: The contrast images showed total stenosis in NTG and GmmcD0, improving to partial stenosis in GmmcD0. In GmmcD14 and Gdil+mmcD14, two animals of each group improved to partial stenosis. By histopathological analysis, NTG and GmmcD14 presented intermediate damage and GmmcD0 and Gdil + mmcD14 severe damage.

CONCLUSION: The use of mitomycin $\mathrm{C}$ had beneficial effects specially when applied immediately after the induction of esophageal lesions.

Key words: Esophageal Stenosis. Mitomycin. Rats. 


\section{Introduction}

The ingestion of caustic substances occurs mainly by patients in the pediatric age group, where the esophageal stenosis is the main complication ${ }^{1}$. Esophageal dilation is the treatment of choice ${ }^{2}$. Several substances have already been tested in cases refractory to dilation but with unsatisfactory results ${ }^{3}$. Mitomycin C (MMC), a chemotherapeutic agent that inhibits protein synthesis and the proliferation of fibroblasts, has been used successfully in cases of esophageal stenosis that are refractory to dilation ${ }^{4-5}$, including the Pediatric Digestive Endoscopy at Botucatu Medical School ${ }^{6}$. However, there are few experimental studies describing how this substance interacts with damaged tissue and the best time window for its use after caustic injury ${ }^{7-9}$. The purpose of this study was to evaluate the effects of the topical application of MMC in rats, with or without associated esophageal dilatation, at different moments after the induction of a caustic oesophageal lesion by $\mathrm{NaOH} 10 \%$

\section{Methods}

The study was approved by the Ethics Committee on Animal Experiments of Botucatu Medical School.

Forty eight male Wistar rats were used on the experiment. The animals were supplied by the University as health, three month old, grown up individuals, weighting between 250 and 450 grams. After a seven day accommodation period, the animals were split into six groups:

- SG (sham group): infusion of $0.9 \%$ saline solution in the distal esophagus without surgical manipulation;

- CG (control group): infusion of $0.9 \%$ saline solution in the distal esophagus, associated with temporary ligation of the organ, performed through a Levine probe;

- NTG (non treated group): induction of a caustic lesion without additional treatment;

- GmmcD0: MMC applied immediately after the induction of a caustic lesion;

- GmmcD14: MMC applied 14 days after induction of a caustic lesion;

- Gdil+mmcD14: esophageal dilation and application of MMC 14 days after caustic lesion.

\section{Techniques}

For the procedure of caustic lesion induction the animals were anesthetized with ketamine and xylazine, both at a dose of $100 \mathrm{mg} / \mathrm{kg}$ of body weight intraperitoneally.

After that, medium laparotomy was performed, with dissection of a $1.5 \mathrm{~cm}$ segment of the abdominal esophagus. A 2.0 cotton thread was tied around the gastroesophageal junction to prevent the alkali to reach the stomach while another 2.0 cotton thread was tied around the esophagus just below the diaphragm, to prevent leakage of the corrosive substance to the remainder of the esophagus or respiratory system. Through the probe previously located in the esophagus, $0.2 \mathrm{~mL}$ of $10 \% \mathrm{NaOH}$ solution was injected. The solution remained in contact with the esophageal wall for a 3 minutes period. After this period, the caustic solution was aspirated and the damaged esophageal segments were rinsed with distilled water for 1 minute. The cotton threads and the probe were removed and the laparotomy incision sutured.

The animals received $10 \mathrm{ml}$ of saline administered intraperitoneally, were fasted for 24 hours, and fed ad libidum thereafter

On GmmcD0 animals, after removing the Levine probe, a double lumen catheter 4Fr with cotton inserted at its distal end was passed through the mouth and positioned on the injured esophageal segment. $0.4 \mathrm{~mL}$ of MMC $0.1 \mathrm{mg} / \mathrm{ml}$ was injected through the catheter, enough to moisten the cotton attached to the distal end. The MMC remained in contact with the injured esophageal wall for a period of $2 \mathrm{~min}$. Then, the $4 \mathrm{Fr}$ catheter was removed and the laparotomy incision was sutured.

On GmmcD14 animals, the double-lumen 4Fr catheter containing cotton at the distal end occurred 14 days after the induced caustic lesion, and was performed under fluoroscopy. The application of MMC was the same as described for the GmmcD0. On Gdil+mmcD14 animals, before insertion of the double lumen catheter, an esophageal dilatation was performed with $5 \mathrm{Fr}$ dilator under fluoroscopy.

All animals were weighed at four evaluation moments; on the 7 th, 14th, 21 th, and 28th days after surgery. On the 7 th and 21 th days after surgery, 4 mice in each group underwent contrast exam of the esophagus. The animals were sacrificed on the 28th day of research by cardiac puncture with $19.1 \% \mathrm{KCl}$ injection under anesthesia. After death, new laparotomy was executed for removal of a fragment of the cross distal esophagus, about $1 \mathrm{~cm}$ long, for histopathological analysis. The cross sections of the distal esophagus were fixed in 10\% formalin and embedded in paraffin. Two 4um histological cuts were stained with Hematoxylin \& Eosin 
(HE), while the other two were stained by Masson Trichrome. The same examiner, who was unaware of the group to which the animal belonged, performed histopathological analysis. The animals that subsequently died were always replaced.

\section{Statistical analysis}

Analysis of Variances method (ANOVA) followed by Tukey method was used for variables presenting normal distribution and homogeneous variances. On other cases, when necessary, the nonparametric Kruskal-Wallis test followed by Multiple Comparison Method was used. The level of significance applied to the tests was $5 \%$.

TABLE 1 - Means and standard deviations of the animal's weight (in grams) in groups and moments.

\section{Results}

Body weight

There was no weight changes significant difference between groups Sham (Gs), control (Gc) and the untreated group (GNT) at all moments studied (Table 1). The groups GmmcD0 and GmmcD14 did not show differences with the groups Gs, Gc and NTG in D7, but showed lower values in D14, with a trend toward recovery in D21 and D28. The group Gdil + mmcD14 did not present differences in D7 compared to the other groups, with lower values for D14 and D21, tending to recovery in D28, but with even lower values than the other groups. The values of the weights between the moments of the same group showed that in all groups was recovery from the initial weight, at D28 (Table 1).

\begin{tabular}{|c|c|c|c|c|c|}
\hline \multirow[b]{2}{*}{ Group } & \multicolumn{5}{|c|}{ Moment } \\
\hline & D0 & D7 & D14 & D21 & D28 \\
\hline SG & $\begin{array}{c}285 \pm 10.6 b \\
\text { B }\end{array}$ & $\begin{array}{c}301.1 \pm 29.1 b \\
\mathrm{~A}\end{array}$ & $\begin{array}{c}352.0 \pm 22.3 \mathrm{a} \\
\mathrm{A}\end{array}$ & $\begin{array}{c}348.9 \pm 17.3 \mathrm{a} \\
\mathrm{A}\end{array}$ & $\begin{array}{c}365.3 \pm 24.6 \mathrm{a} \\
\mathrm{A}\end{array}$ \\
\hline $\mathrm{CG}$ & $\begin{array}{c}348.5 \pm 69^{\mathrm{a}} \\
\mathrm{A}\end{array}$ & $\begin{array}{c}308.5 \pm 61.7 b \\
\mathrm{~A}\end{array}$ & $\begin{array}{c}333.4 \pm 55.8 \mathrm{ab} \\
\mathrm{A}\end{array}$ & $\begin{array}{c}345.4 \pm 61.7 \mathrm{a} \\
\mathrm{A}\end{array}$ & $\begin{array}{c}358.3 \pm 61.7 \mathrm{a} \\
\mathrm{AB}\end{array}$ \\
\hline NTG & $\begin{array}{c}310.9 \pm 44.5 b c \\
\text { B }\end{array}$ & $\begin{array}{c}304.5 \pm 39.6 \mathrm{c} \\
\mathrm{A}\end{array}$ & $\begin{array}{c}339.5 \pm 41 \mathrm{ab} \\
\mathrm{A}\end{array}$ & $\begin{array}{c}343.6 \pm 23.8 \mathrm{a} \\
\mathrm{A}\end{array}$ & $\begin{array}{c}363.8 \pm 40.2 \mathrm{a} \\
\mathrm{A}\end{array}$ \\
\hline GmmcD0 & $\begin{array}{c}306.1 \pm 26.4 \mathrm{abc} \\
\text { B }\end{array}$ & $\begin{array}{c}290.0 \pm 32.3 \mathrm{c} \\
\mathrm{A}\end{array}$ & $\begin{array}{c}302.5 \pm 43.3 \mathrm{~b} \\
\mathrm{~B}\end{array}$ & $\begin{array}{c}330.8 \pm 39.2 \mathrm{ab} \\
\mathrm{AB}\end{array}$ & $\begin{array}{c}342.9 \pm 32.7 \mathrm{a} \\
\mathrm{BC}\end{array}$ \\
\hline GmmcD14 & $\begin{array}{c}297.6 \pm 17.3 \mathrm{ab} \\
\text { B }\end{array}$ & $\begin{array}{c}296.3 \pm 16.7 \mathrm{ab} \\
\mathrm{A}\end{array}$ & $\begin{array}{c}289.8 \pm 28.1 b \\
\text { B }\end{array}$ & $\begin{array}{c}307.1 \pm 26.3 \mathrm{ab} \\
\mathrm{B}\end{array}$ & $\begin{array}{c}320.3 \pm 22.3 a \\
C\end{array}$ \\
\hline $\begin{array}{c}\text { Gdil+ } \\
\text { mmcD14 }\end{array}$ & $\begin{array}{c}291.8 \pm 25.7 \mathrm{ab} \\
\mathrm{B}\end{array}$ & $\begin{array}{c}283.6 \pm 35.3 b \\
\text { A }\end{array}$ & $\begin{array}{c}299.1 \pm 45.2 \mathrm{ab} \\
\text { B }\end{array}$ & $\begin{array}{c}307.5 \pm 35.3 \mathrm{ab} \\
\text { B }\end{array}$ & $\begin{array}{c}315.4 \pm 32.8 \mathrm{a} \\
\mathrm{C}\end{array}$ \\
\hline
\end{tabular}

$\mathrm{P}=0.14$ for groups, $\mathrm{p}<0.0001$ for moments and for moments $\mathrm{x}$ groups Lowercase letters compare means of the moments in each group

Uppercase letters compare means of the groups in each moment

TABLE 2 - Obits and mortality rates in the different groups.

\section{Mortality}

The rats in the SG and CG remained alive until day 28. However, in the groups submitted to infusion of caustic soda, mortality was higher, as shown in Table 2.

\begin{tabular}{ccc}
\hline GROUPS & OBITS & $\mathbf{\%}$ \\
\hline SG & 0 & 0 \\
CG & 0 & 0 \\
NTG & 3 & 6.25 \\
GmmcD0 & 4 & 8.3 \\
GmmcD14 & 3 & 6.25 \\
Gdil+mmcD14 & 5 & 10.4 \\
\hline
\end{tabular}




\section{Esophageal contrast radiography}

The esophageal radiological study was performed in two moments: 7th and 21th days postoperatively, where it was observed that mice of SG, which did not suffer any type of surgical procedure, showed no esophageal stenosis or motility dysfunction.

The rats in CG showed mild stenosis on postoperative day 7 and motility dysfunction (slowing of esophageal clearance) on the 21 th postoperative day.

The GNT group, which received caustic soda without any treatment, showed severe stenosis in the first moment, since the distal esophagus presented with smaller diameter and did not allow the passage of contrast into the stomach. The stenosis was maintained, and in some cases even worsened with time.

In GmmcD0, that received MMC at the same moment of caustic injury, all animals presented with total stenosis on day 7 , which became partial at day 21 (Figure $1 \mathrm{~A}-\mathrm{B}$ ).

In GmmcD14, where MMC was applied 14 days after caustic injury, from the 4 animals studied, 2 had partial stenosis on day 7, with improvement at day 21 (Figure $1 \mathrm{C}-\mathrm{D}$ ). The other two animals had total stenosis in the first moment, what was maintained at day 21 .

In Gdil + mmcD14, all 4 animals showed total stenosis in the first moment. Of these, two progressed to partial stenosis (Figure $1 \mathrm{E}-\mathrm{F}$ ) and 2 showed no changes at day 21.

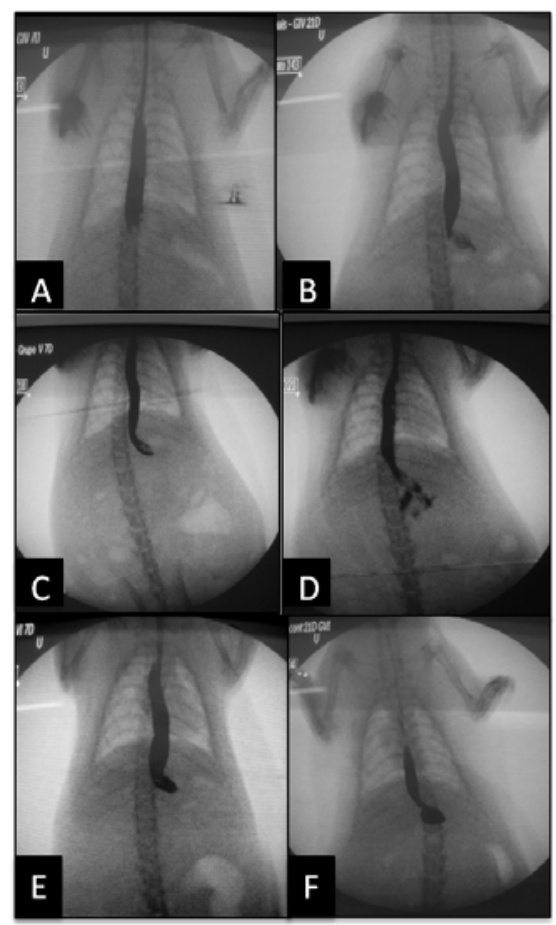

FIGURE 1 - Contrast X-rays of the esophagus on 7th and 21th days after caustic injury: $G m m c D 0$ (A and B), GmmcD14 (C and D) and $G d i l+m m c D 14(\mathbf{E}$ and $\mathbf{F})$.

\section{Histopathological analysis}

Histopathological analysis were performed according to the following criteria: increased collagen in the submucosa, damage in the muscularis mucosa and damage and deposition of collagen in the muscular layer.

We observed that there was a marked increase of collagen in the submucosa in the Gdil + mmcD14, followed by lesser intensity in GmmcD14 and GmmcD0. The CG rats did not show changes in the submucosa.

In assessing the damage only to the muscularis mucosa, the rats of SG and CG showed no damage. In contrast, NTG and Gdil+ mmcD14 rats showed very similar results, both with intense muscularis mucosa damage, followed by GmmcD0 and GmmcD14, where the damage was intermediate.

In the evaluation of the damage and collagen deposition in the muscular layer, once again the rats of SG and CG showed no injury. Rats of GmmcD0 and Gdil+mmcD14 showed a severe damage in the muscular, whereas rats of the NTG and GmmcD14 had slight damage (Figure 2).

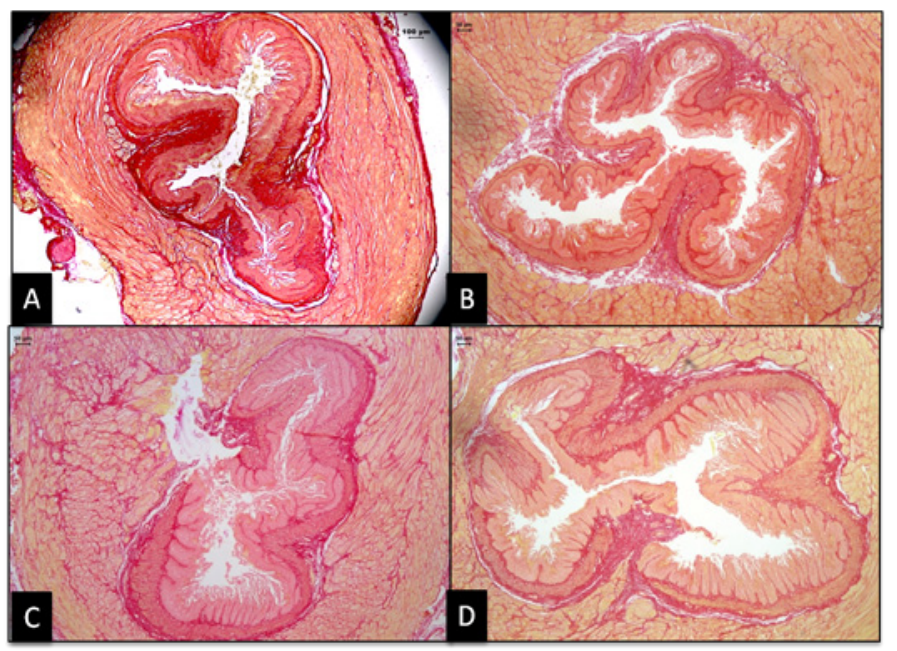

FIGURE 2 - Histopathologic analysis of distal esophagus transverse sections: A: CG - no histopathological changes (H\&E, 20x), B: NTG damage to the muscularis mucosa with little increase in collagen in the submucosa (H\&E, 40x), C: GmmcD0 - intense damage to the muscularis mucosa and significant damage and collagen deposition in the muscular layer (H\&E, 40x), D: Gdil+ mmcD14 - significant increase in collagen in the submucosa and in the muscular and intense damage to the muscular mucosa (H\&E, 40x).

\section{Discussion}

The acidental caustic esophageal injury is the most common cause of esophageal stenosis in childhood ${ }^{1}$. In the study of Keskin et al. ${ }^{10}$, sodium hydroxide $(\mathrm{NaOH})$ was the only caustic 
agent involved in all patients with esophageal stenosis requiring surgical replacement of the organ. Thus, in the experimental studies, $\mathrm{NaOH}$ has been used as a caustic agent ${ }^{8-9}$. Although it has been instilled at different concentrations and different times in the various studies, the most important is the creation of a lesion of enough intensity to cause a stenosis without resulting in perforation of the organ. This was obtained in our research with the application of 0.1 to $0.2 \mathrm{ml}$ of $\mathrm{NaOH} 10 \%$ for 3 minutes in the rats' distal esophagus.

Alkali ingestion cause liquefaction necrosis with deep penetration in the esophageal tissue. The necrotic detachment occurs within the first four to seven days, when there is a predominance of acute inflammatory response. In the second week after injury, occurs fibroblast proliferation and collagen deposition, with consequent formation of esophageal stricture, which is completed up to 28 to 42 days $^{11}$. Thus, a potential pharmacological treatment which helps prevent stenosis tend to be beneficial if used within this period, preferably before the end of the third week after injury. For this reason, the application moments of MMC in this study were at D0 (day of caustic injury) and D14 (14 days after caustic injury), when stenosis should already be installed.

The treatment of choice for esophageal stenosis remains serial dilations ${ }^{12}$. Although it is a relatively safe and effective procedure for children, complications and treatment failures occur frequently associated with caustic stenosis ${ }^{13}$. Repeated dilatations of the injured esophagus, causes a recurrent mucosal damage, what leads to an increase in scar formation with fibroblast proliferation and collagen deposition, worsening the stenosis ${ }^{13}$. These data corroborates with our results.

Mitomycin C decreases fibroblast collagen synthesis, inhibiting the synthesis of RNA and also suppresses cell proliferation at any stage of mitotic cycle, particularly in the late G2 phase. This antineoplastic agent proved to be a strong inhibitor of fibroblast proliferation both in vitro and in vivo ${ }^{14-15}$. Jang et al. ${ }^{16}$ studied the effects of topical application of MMC in fibroblast cultures and observed that the antiproliferative effect of MMC occurred at low concentrations, from $0.1-0.4 \mathrm{mg} / \mathrm{ml}$ after periods of 5 to 10 minutes of exposure. Turkyilmaz et al. ${ }^{9}$ in a studying how to prevent caustic esophageal stricture in rats, noticed better results with topical MMC $0.04 \%$ during 5 minutes when compared to $0.02 \%$. High doses of MMC tend to be cytotoxic to fibroblasts, whereas lower doses exhibit an antiproliferative effect. Simman et al. ${ }^{17}$ reported that the new fibroblasts growth occur two to three weeks after the application of MMC, while Occleston et al. ${ }^{18}$ showed that the antiproliferative effect of MMC can last for up to 48 days. In 2008, Ortolan et al. ${ }^{6}$ reported four cases of children with caustic esophageal stenosis, refractary to dilations. After the use of topical MMC $0.1 \mathrm{mg} / \mathrm{ml}$ for $2 \mathrm{~min}$ after dilations, two children had no longer dysphagia and two could prolong the interval between dilations. Based on the case reported by Afzal et al. ${ }^{4}$ and in the protocol for the MMC use in the Pediatric Endoscopy Unit at Botucatu Medical School, the dose and duration of application of MMC at the presente study were determined in $0.1 \mathrm{mg} / \mathrm{ml}$ for 2 minutes.

One of the MMC advantages is its possibility to be administered topically, without adverse systemic effects, and is commercially available at low cost. The subcutaneous infiltration of MMC when administered intravenously, can cause ulcers, tissue necrosis or detachment. The contact with MMC when applied topically can result in tissue detachment when in high concentrations. In addition to these effects, the long-term use of this drug can lead to secondary malignancy, which becomes an extra concern when used in children. It should be emphasized that the mutagenic effects of MMC have not been studied when used in caustic esophageal lesions. Bakshi et al. ${ }^{19}$ showed that MMC significantly induced many chromosomal aberrations in cultured peripheral blood lymphocytes in children with cancer and their descendants in the first degree, when compared to the control group. Therefore, special considerations should be given to children with positive family history of malignancy, when the use of MMC is considered to treat caustic esophageal strictures. In the other hand, although MMC's mutagenic properties, no malignancy was reported in a review of ten years with 870 cases of pterygium treated with MMC at a dose of $0.4 \mathrm{mg} / \mathrm{ml}^{20}$.

\section{Conclusion}

The use of topic MMC in this experimental esophageal caustic injury model had benefical effects, especially if used right after the injury.

\section{References}

1. Broto J, Asensio M, Soler JC. Conservative treatment of caustic injuries in children: 20 years of experience. Pediatr Surg Int. 1999;15:323-5.

2. Ferreira CT, Pretto FM, Angeli C, Nunes DA, Zim MC, Cantalice Neto A, Ferreira PR, Minuzzi R. Estenose de esôfago na criança: etiologia, aspectos clínicos e resultados de dilatações com SavaryGilliard. GED. 2003;22:61-7.

3. Demirbilek S, Bernay F, Rizalar R, Bariş S, Gürses N. Effects of estradiol and progesterone on the synthesis of collagen in corrosive esophageal burns in rats. J Pediatr Surg. 1994;29:1425-8.

4. Afzal NA, Albert D, Thomas AL, Thomson M. A child with oesophageal strictures. Lancet. 2002;359(9311):1032. 
5. Uhlen S, Fayoux P, Vachin F, Guimber D, Gottrand F, Turck D, Michaud L. Mitomycin C: an alternative conservative treatment for refractory esophageal stricture in children? Endoscopy. 2006;38(4):404-7.

6. Ortolan EVP, Bustamante TF, Takegawa BK, Mendonça FA, Rodrigues AM, Mendes EF. Therapeutic option for children with esophageal caustic stenosis. Dig Endoscopy. 2008;20(3):146-9.

7. Gehanno P, Guedon C. Inhibition of experimental esophageal lye strictures by penicillamine. Arch Otolaryngol. 1981;107:145-7.

8. Türkyilmaz Z, Sönmez K, Demirtola A, Karabulut R, Poyraz A, Gülen S, Dinçer S, Başaklar AC, Kale N. Mitomycin C prevents strictures in caustic esophageal burns in rats. J Surg Res. 2005;123(2):182-7.

9. Türkyilmaz Z, Sönmez K, Karabulut R, Gülbahar O, Poyraz A, Sancak B, Başaklar AC. Mitomycin C decreases the rate of stricture formation in caustic esophageal burns in rats. Surgery. 2009;145:219-25.

10. Keskin E, Okur H, Koltuksuz U, Zorludemir U, Olcay I. The effect of steroid treatment on corrosive oesophageal burns in children. Eur J Pediatr Surg. 1991;1(6):335-8.

11. Rothstein FC. Caustic injuries to the esophagus in children. Pediatr Clin North Am. 1986;33(3):665-74.

12. Siersema PD, de Wijkerslooth LR. Dilation of refractory benign esophageal strictures. Gastrointest Endosc. 2009;70(5):1000-12.

13. Rosseneu S, Afzal N, Yerushalmi B, Ibarguen-Secchia E, Lewindon P, Cameron D, Mahler T, Schwagten K, Köhler H, Lindley KJ, Thomson M. Topical application of mitomycin $\mathrm{C}$ in oesophageal strictures. J Pediatr Gastroenterol Nutr. 2007;44:336-41.

14. Chabner BA, Ryan DP, Paz-Ares L, Garcia-Carbonero R, Calabresi P. Antineoplastic agents. In: Goodman \& Gilman's, The pharmacological basis of therapeutics (Hardman JG, Limbird LE, eds). New York: McGraw-Hill Medical Publ Division; 2001. p.1389-459.

15. Majmudar PA, Forstot SL, Dennis RF, Nirankari VS, Damiano RE, Brenart R, Epstein RJ. Topical mitomycin C for subepithelial fibrosis after refractive corneal surgery. Ophtalmology. 2000;107:89-94.

16. Jang $\mathrm{CH}$, Song $\mathrm{CH}$, Pak SC. Effect of exposure to mitomycin $\mathrm{C}$ on cultured tympanic membrane fibroblasts. Int $\mathrm{J}$ Pediatr Otorhinolaryngol. 2003;67:173-6.

17. Simman R, Alani H, Williams F. Effect of mitomycin C on keloid fibroblasts: an in vitro study. Ann Plast Surg. 2003;50:71-6.

18. Occleston NL, Daniels JT, Tarnuzzer RW, Sethi KK, Alexander RA, Bhattacharya SS, Schultz GS, Khaw PT. Single exposures to antiproliferatives: long term effects on ocular fibroblasts wound healing behavior. Invest Ophthalmol Vis Sci. 1998;38:1997-2007.

19. Bakshi SR, Patel RK, Roy SK, Alladi P, Trivedi AH, Bhatavdekar JM, Patel DD, Shah PM, Rawal UM. Mitomycin C induced chromosomal aberrations in young cancer patients. Mutat Res. 1998;422:223-8

20. Anduze AL. Pterygium surgery with mitomycin C: ten year results. Ophthalmic Surg Lasers. 2001;32:341-5.

\section{Correspondence:}

Erika Veruska Paiva Ortolan

Distrito de Rubião Júnior, s/n

18618-000 Botucatú - SP Brasil

Tel./Fax: (55 14)3815-7428

epaiva@fmb.unesp.br

Received: September 25, 2012

Review: November 26, 2012

Accepted: December 20, 2012

Conflict of interest: none

Financial source: Sao Paulo Research Foundation (FAPESP)

${ }^{1}$ Research performed at Botucatu Medical School, State University of Sao Paulo (UNESP), Botucatu-SP, Brazil. Part of Master degree Thesis, Postgraduate Program in General Basis of Surgery, UNESP. Tutor: Erika Veruska Paiva Ortolan. 